\section{Ludwig van Beethoven, el genio de Bonn atormentado por sus enfermedades: su historia médica}

\author{
MARCELO MIRANDA
}

\section{A medical biography of Ludwig van Beethoven}

Much emphasis has been given to the deafness of Ludwig van Beethoven and its potential causes. However, when analyzing several symptoms reported by himself throughout his life in many letters and his final illness, a common etiology emerges. This article reports the medical history of this artist, based on authoritative scientific sources.

(Rev Med Chile 2018; 146: 91-95)

Key words: Autoimmune diseases; Deafness; Famous Persons.

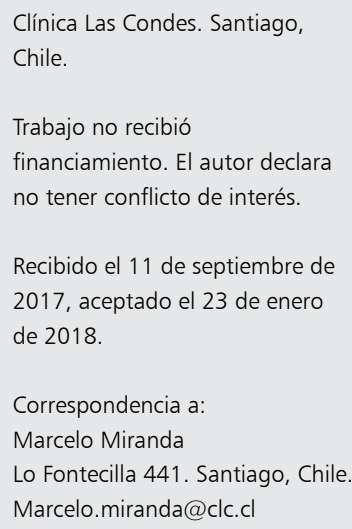

Correspondencia a:

Marcelo Miranda

Lo Fontecilla 441. Santiago, Chile

Marcelo.miranda@clc.cl

Existen pocos ejemplos en la historia de la música más impactantes que el de Ludwig van Beethoven (Figura 1$)^{1}$, en cuanto a los efectos que una enfermedad puede producir en la vida de un artista o que, a pesar de ella, se logren realizar obras maestras. Ese es el caso de Beethoven, quien aquejado de una sordera precoz, se vio severamente invalidado por este déficit en los aspectos sociales, no obstante, no disminuyó su genio creativo.

Obras portentosas como la Novena Sinfonía, fueron escritas estando completamente sordo. Aún existen controversias acerca del origen de su defecto auditivo, como también de la etiología del síndrome hepatorrenal que le provocó la muerte, o si existió una causa común para estos 2 trastor$\operatorname{nos}^{2-6}$. Los intentos para determinar el origen de su sordera llevaron en 2 ocasiones a exhumar sus restos en 1863 y 1888, sin mayor aporte.

En este documento, se presentan aspectos médicos poco conocidos de la vida de Beethoven, que permiten plantear un diagnóstico etiológico de sus síntomas.

\section{Su historia médica}

Beethoven nació el 16 de diciembre de 1770 en Bonn, Alemania, en una familia humilde. Fue el segundo de 7 hijos, de los cuales sobrevivieron sólo 3, incluyendo sus hermanos Karl y Johann. Su padre, que era tenor en la capilla del elector de Colonia, lo impulsó a estudiar música muy tempranamente, imponiéndole una dura disciplina en sus tareas. Mostrando un talento impresionante, dio su primer concierto público a los 7 años, y a los 12 publicó su primera composición. Su padre falleció víctima del alcoholismo cuando Beethoven tenía 21 años. Su madre había fallecido de tuberculosis pocos años antes, cuando él tenía 17 años. Beethoven permaneció en Bonn los primeros 22 años de su vida, pero luego de la muerte de su padre, se trasladó con su familia a Viena, debiendo encargarse de solventar su hogar. Durante los primeros 20 años de su vida poco se sabe de su historia médica, salvo que era asmático desde los 5 años y que continuó teniendo un "débil tórax". Sin embargo, se desconoce si tuvo tuberculosis. Sí se sabe que padeció de varicela, la que dejó secuelas de cicatrices faciales ${ }^{2}$.

Desde los 22 años, Beethoven presentó sintomatología digestiva que lo acompañó toda la vida. Tuvo períodos intercurrentes de diarrea, en raras ocasiones sanguinolenta, dolor abdominal tipo cólico, el que inicialmente la ingesta de alcohol lo aliviaba ${ }^{2-4}$.

Su defecto auditivo, que ya era notorio a los 27 años, comenzó en el oído izquierdo y luego se hizo bilateral ${ }^{2-4}$. La hipoacusia era frente a sonidos 


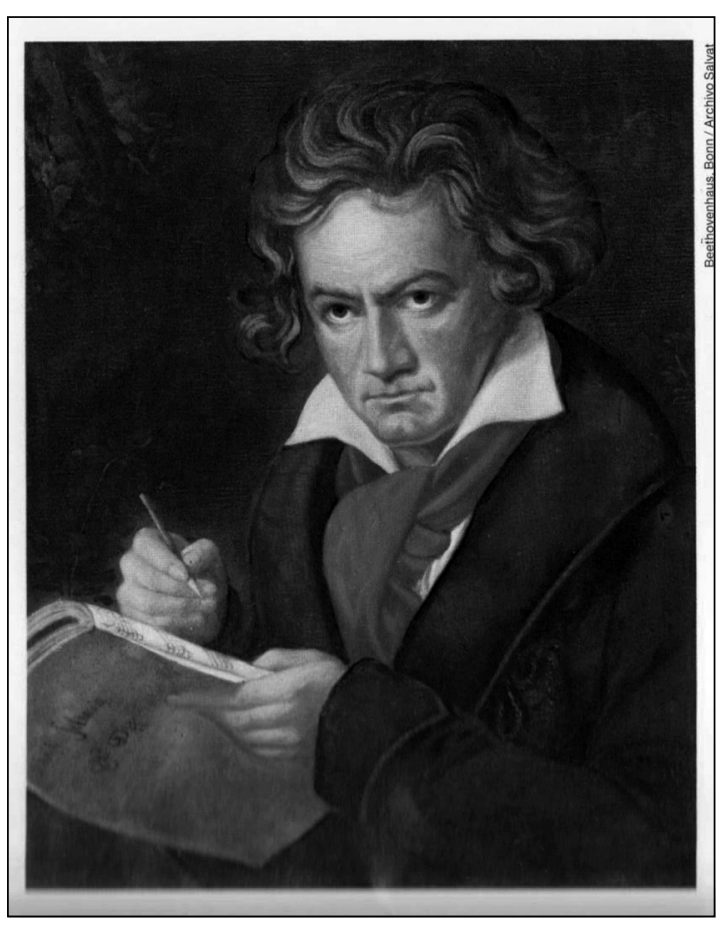

Figura 1. Beethoven, ya sordo, escribiendo la Misa solemnis, en 1819 .

de alta frecuencia, asociada a severo tinnitus, con pobre discriminación y reclutamiento, indicador de compromiso sensorio-neural. Beethoven usó elementos como trompetas de oído, y una varilla de madera que colocaba en sus dientes (y el otro extremo apoyado en el piano para intentar oír mejor) (Figura 2) $)^{1,2}$. Sin embargo, no fueron de real utilidad, ya que el defecto era principalmente sensorio-neural y no de conducción. Mantuvo oculto su déficit por 3 años y recién lo manifestó a su amigo Wegeler en cartas de 1801: "déjeme contarle que mi más preciada posesión, mi audición, se ha deteriorado en estos últimos 3 años, he estado muy desesperado. Para darle una idea en el teatro estoy obligado a inclinarme hacia el escenario para entender a los actores o músicos y por momentos no escucho nada de notas altas de que ellos dan. Frecuentemente, puedo oír una conversación en bajo volumen, pero no logro distinguir las palabras"8,9. Ya a esta edad manifestó depresión "el cielo solo sabe lo que va ser de mí... me informaron que mi sordera no tiene cura. Ya he maldecido a mi creador y a mi existencia. $\mathrm{Ud}$.

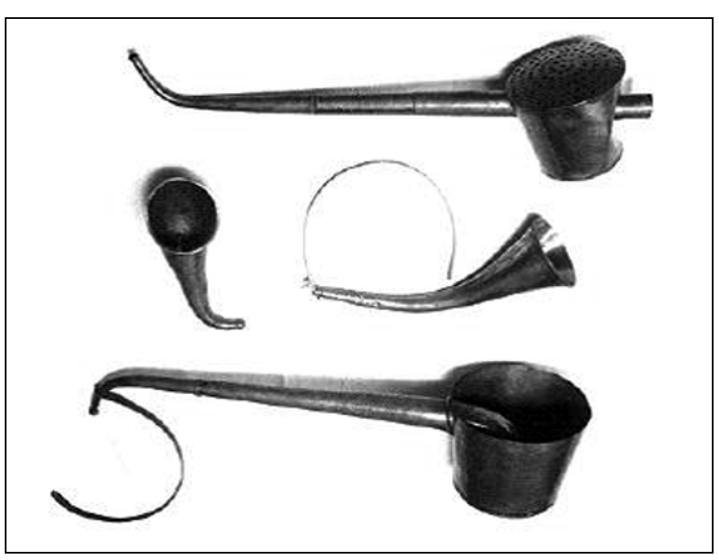

Figura 2. Los implementos que Beethoven usó para ayudarse en su sordera desde 1814.

puede darse cuenta qué triste vida debo tener, viendo que he sido retirado de todo lo que es querido y precioso para mí... debo retirarme de todo". El defecto auditivo produjo en Beethoven una pérdida de la autoestima, labilidad emocional, aislamiento progresivo y negligencia con sí mismo. En varias cartas manifestó ideación suicida, que sólo fue evitada por su sentido moral y el amor a la música: "hace una semana en el campo, el no poder escuchar el sonido de una flauta me provocó tanta desesperación que por poco más pongo fin a mis días, solo mi arte fue lo que me hizo retroceder"2.

En 1812, el músico Ludwig Spohr escribió: “era tarea difícil hacerse entender por Beethoven, uno tenía que gritar tan fuerte que podría oírse a tres habitaciones más allá" ${ }^{8,9}$. Entre 1812 y 1814 (41-45 años de edad), todas sus visitas tenían que gritar para hacerse entender. En 1814 comenzó a usar las trompetas de oído. En enero de 1815 fue su última presentación pública. En 1817 ya no pudo escuchar música y debió usar libros de conversación, en los cuales sus interlocutores se comunicaban con Beethoven a través de la escritura ${ }^{2,8,9}$. En 1818 la audición no le permitía la comunicación oral a pesar de los implementos que usaba. Desde los 50 años, es decir 1820, estaba funcionalmente sor$\mathrm{do}^{2,8,9}$. En 1822 intentó conducir su ópera Fidelio, pero fue forzado a abandonar el intento. Después de 1822, Beethoven no vuelve más a intentar ayuda médica. En 1824, a la edad de 54 años, en la première de su 9a Sinfonía, no pudo percatarse de la ovación que estaba recibiendo hasta que una de 
las cantantes, la contralto Karoline Ungar, lo hace girar de cara al público ${ }^{2,89}$. En esos años, Beethoven se vuelve negligente consigo mismo, comienza a ingerir alcohol con frecuencia, especialmente ponche y vino de la variedad húngara. Se le veía frecuentemente caminando solo en las calles sin sombrero, con un viejo abrigo y una apariencia descuidada. Su comportamiento llegó a ser extraño, con frecuentes ataques de irritabilidad. Su relación con los médicos era peor que nunca y frecuentemente los descalificaba. En este período eran frecuentes sus quejas de problemas diarreicos y también malestares reumáticos ${ }^{2}$.

La sordera tuvo un importante papel en las composiciones de Beethoven, las que pueden dividirse en 3 períodos de acuerdo a sus biógrafos. El primero, que se extiende hasta 1800 y que corresponde al inicio de su sordera, muestra la influencia de sus maestros Haydn y Mozart. El período medio corresponde al inicio y progresión de su sordera (1800-1815), durante el cual compone su hermosa sonata Claro de Luna y las Tercera, Cuarta, Quinta y Sexta Sinfonías. El último período coincide con su total sordera y severa enfermedad sistémica. En este período de "silencio" es que compuso la grandiosa Novena Sinfonía, la Misa Solemnis los últimos 6 cuartetos de cuerdas y las últimas sonatas para piano 2 .

La mayor parte de la música que por siempre ha influido y sobrecogido a millones de seres humanos desde entonces surgió de la mente de este hombre que no pudo escuchar nada de ella.

\section{La sintomatología digestiva hasta su final y su etiología más plausible}

Desde los 22 años Beethoven presentó diarrea recurrente con dolor abdominal, que derivaron en una severa postración y anorexia ${ }^{2,3}$. Estos episodios aumentaron en severidad, frecuencia y duración con el paso del tiempo. En 1821, tuvo un prolongado episodio de ictericia, dolor abdominal y vómitos. La ictericia persistió por meses, volviendo a presentarse en un segundo episodio en $1825^{2}$. En los últimos 3 meses de vida manifestó claramente signos de insuficiencia hepática, gatillados por cuadros de neumonía en diciembre de 1826 y a principios de marzo de $1827^{2}$. Se hizo evidente una ascitis marcada, requiriendo en cuatro oportunidades paracentesis, practicadas por el
Dr. Andreas Wawruch, drenándose hasta 22 litros en una ocasión. Presentó una nueva neumonía 15 días antes del desenlace fatal.

Falleció el 26 de marzo de 1827 a las $18 \mathrm{~h}$ de lo que ahora se conoce como síndrome hepatorrenal, probablemente agravado por una peritonitis bacteriana espontánea ${ }^{2,3,6}$. La escena de la muerte es revivida por uno de los presentes, Anselm Huttenbrenner: "a eso de las 5.30 PM se vio un rayo seguido de un gran trueno, iluminándose el lecho de Beethoven, quien abrió sus ojos, levantó su mano derecha y con la mano empuñada dijo: poderes hostiles, los desafió, Dios está conmigo" $\mathrm{Al}$ dejar caer la mano, sus ojos se cerraron a medias. No se sintió más respiración ni más latidos cardiacos". Su funeral tuvo una asistencia calculada en 20.000 personas $^{8-10}$ (Figura 3).

La causa de su daño hepático se ha atribuido al abuso del alcohol. Esta hipótesis es bastante discutible, ya que algunos de los médicos que lo atendieron en la etapa final de su vida afirmaron que Beethoven era un bebedor muy discreto y solo exageró el uso en relación al último período de su vida para calmar los dolores abdominales. Uno de sus amigos, su médico Wegeler, afirmó más tarde que ninguno de sus amigos o conocidos jamás lo

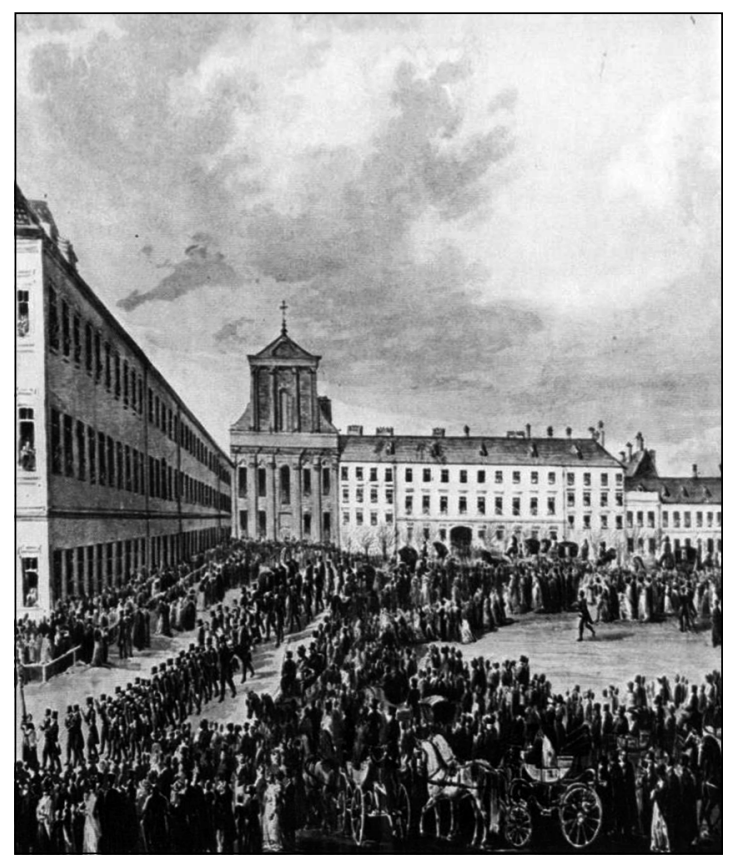

Figura 3. Los funerales del músico en Viena, con 20.000 asistentes. 
vieron en estado de embriaguez. Beethoven mismo atribuyó siempre que todos sus problemas de salud se generaron de su diarrea de inicio en la juventud, incluso su defecto auditivo ${ }^{2,4}$.

\section{Hallazgos de la necropsia}

Otro hecho que está en contra de la etiología alcohólica de su cirrosis, es que la autopsia realizada el día posterior a su fallecimiento por Wagner y Rokitanski (la que sería la primera de las 59.786 autopsias realizadas por este último) mostró una cirrosis macronodular y no micro como suele verse en el alcoholismo. Los hallazgos más relevantes de la autopsia en el abdomen fueron: cirrosis del hígado de la variedad macronodular, signos de hipertensión portal con el bazo 3 veces el tamaño normal. Había 9 litros de líquido ascítico infectado en la cavidad peritoneal. El páncreas estaba endurecido, compatible con una pancreatitis crónica y había colelitiasis. En cabeza y cuello, comentaron que el cráneo estaba engrosado (0,5 pulgadas de grosor). Los nervios auditivos estaban adelgazados (más el izquierdo que el derecho) y las arterias auditivas estaban ateroscleróticas. El hueso temporal y su contenido fue removido para un análisis más exhaustivo, pero se extraviaron sus rastros ${ }^{2,3,9}$.

La hipótesis de una enfermedad inflamatoria intestinal como colitis ulcerosa o Crohn, postulada por Davies y Kubba y $\mathrm{col}^{2,3}$, es muy interesante. Esta etiología autoinmune, que comprende además la asociación con una cirrosis hepática por colangitis esclerosante primaria, también podría explicar su defecto auditivo. Esto dado que, en las manifestaciones extra digestivas está presente la hipoacusia sensorioneural. Sin embargo, llama la atención la ausencia de mayor comentario en la autopsia, acerca de la presencia de estenosis, perforaciones y adherencias como las que se ven en Crohn, ni de referencias en sus cartas a importante sangrado digestivo bajo, como se ve en la colitis ulcerosa.

\section{$\underline{\text { Las hipótesis sobre la etiología de su sordera }}$}

\section{Enfermedad de Paget:}

Se ha planteado una enfermedad de Paget. Esto está basado en que Beethoven era macrocefálico $y$ en los hallazgos de la autopsia que revelaron un engrosamiento del hueso craneal. Sin embargo, la enfermedad de Paget se manifiesta en un grupo etario mayor, el engrosamiento craneal es focalizado y no difuso como en Beethoven. Tampoco explica los síntomas gastrointestinales. El defecto auditivo en Paget es usualmente mixto, con un componente importante de conducción y casi nunca se presenta entre los 20 y 30 años, como en Beethoven. Finalmente, Jesserer y Banal analizaron restos del cráneo presuntamente de Beethoven y no encontraron evidencia de esta enfermedad ${ }^{11}$. Sin embargo, una reciente interpretación de los resultados de autopsia por Oiseth hace plantear a este autor que sí era compatible con enfermedad de Paget $^{12}$.

\section{Otoesclerosis}

Es una enfermedad autosómico dominante de la capsula ótica que puede causar hipoacusia de conducción, mixta o, más raramente, de tipo sensorioneural. No hay historia familiar que la apoye. Se presenta generalmente como una hipoacusia de conducción en la adolescencia y progresa lentamente. No existen casos comunicados en que no haya compromiso del estribo. En la autopsia de Beethoven no se menciona este compromiso ni signos de fijación ósea².

\section{Intoxicación con plomo}

El reciente hallazgo de residuos de plomo en fragmentos del cabello de Beethoven ${ }^{13}$ hicieron pensar en una intoxicación con plomo como causa de sus problemas digestivos, pero no podría explicar el defecto auditivo (aunque hay controversia al respecto $)^{14}$, ni el daño hepático crónico. La fuente de los altos niveles de plomo se ha atribuido al agregado de plomo que en esa época se hacía en los vinos o el envase en que se guardaban ${ }^{13,14}$.

\section{Sifilis}

Esta hipótesis es poco sostenible; está basada en 2 prescripciones de mercurio que habría tenido Beethoven en 1820. El mercurio era utilizado no solo para tratar sífilis sino un sin fin de males, y recientemente se ha confirmado que la prescripción era en realidad un compuesto de amonio. La manifestación auditiva de la lúes es de presentación tardía y no a la edad en que Beethoven tuvo sus primeros síntomas, y cuando aparece hipoacusia por lúes, habitualmente ya existen manifestaciones de tabes o parálisis general; ninguna evidencia clínica la favorece ${ }^{2}$. 


\section{Enfermedad inflamatoria intestinal}

En esta enfermedad sistémica es posible observar manifestaciones neurológicas tanto en la colitis ulcerosa como en la enfermedad de Cro$\mathrm{hn}$; ambas pueden acompañarse de hipoacusia sensorioneural ${ }^{15-18}$. Esta asociación fue descrita inicialmente por Levitar ${ }^{15}$ y diversos autores posteriores han confirmado su presencia ${ }^{16-18}$. Incluso está presente en pacientes sin síntomas otológicos: en una serie de 20 pacientes con colitis ulcerosa pudo detectarse, con audiometría de tonos puros, una significativa hipoacusia sensorioneural en el grupo de pacientes comparado con controles ${ }^{16}$.

\section{Manifestaciones reumáticas asociadas}

En concomitancia con los síntomas digestivos ,Beethoven manifestó con frecuencia síntomas articulares. En 2 ocasiones presentó abscesos que comprometieron dedos de una mano y luego su mandíbula ${ }^{19}$. En 1822 se comunicó una "gota torácica" que se repitió posteriormente, sin embargo, no se explicitaron qué síntomas manifestó. Entre agosto de 1823 y junio de 1824 hizo varias referencias a dolor ocular, lo que sugiere la presencia de una uveítis ${ }^{2,9}$. Esta manifestación, en conjunto con la sintomatología artrálgica y diarrea recurrente, hacen plantear una etiología inmunitaria común. Beethoven siempre hizo referencia a un episodio febril inicial en 1792 con diarrea que, según él, causaría todos sus males posteriores ${ }^{2,3,8,9,19}$. Se ha planteado que esta probable disentería haya provocado una artritis reactiva seronegativa, con sacroileítis, espondilitis anquilosante y uveítis recurrentes, entre otras manifestaciones ${ }^{19}$. Es una gran ironía que un genio que aportó una creación artística musical que ha maravillado y emocionado a la humanidad desde entonces, haya por sí mismo luchado contra un mundo en silencio prácticamente la mitad de su vida. Del punto de vista médico, como otros autores, concordamos con el mismo Beethoven, quien atribuyó su sordera a sus problemas digestivos crónicos; la etiología que mejor explica la mayoría de sus síntomas es una enfermedad inflamatoria intestinal.

\section{Referencias}

1. http://www.fraunhofer.de/archiv/presseinfos/pflege. zv.fhg.de/german/press/pi/pi2002/08/md_fo6a.html

2. Kubba A,Young M. Ludwig van Beethoven: a medical biography. Lancet 1996; 347: 167-70.

3. Karmody C, Bachor E. The deafness of Ludwig van Beethoven: an Immunopathy. Otology and Neurotology 2005: 24: 809-14.

4. Shearer P. The deafness of Beethoven: an audiologic and medical overview. Am J Otology 1990; 11: 370-4.

5. Chalat N. Some psychologic aspects of Deafness; Beethoven, Goya and Oscar Wilde. Am J Otology 1980; 1: 240-6.

6. Mai FM. Beethoven's terminal illness and death. J R Coll Physician Edinb 2006; 36: 258-63.

7. Huxtable R. The deafness of Beethoven: a paradigm of hearing problems. Proc West Pharm Soc 2000; 43: 1-8.

8. Landon HR. Beethoven. Thames and Hudson, Londres 1978.

9. Herriot E. Beethoven. Aguilar. Madrid. 1964.

10. http://www.starnews2001.com.br/beethoven/galeria.htm

11. Jesserer H, Bankl H. Was Beethoven's deafness caused by Paget's disease? Report of findings and study of skull fragments of Ludwig van Beethoven.Laryngol-Rhinol-Otol 1986; 65: 592-7.

12. Oiseth SJ. Beethoven's autopsy revisited: A pathologist sounds a final note. J Med Biogr 2017; 25 (3): 139-47. http://www.anl.gov/Media_Center/Frontiers/2002/ c3facil.html

14. Stevens MH, Jacobsen T, Crofts AK. Lead and the deafness of Ludwig van Beethoven. Laryngoscope 2013; 123 (11): 2854-8.

15. Levitan $\mathrm{H}$. The etiologic significance of deafness in ulcerative colitis Int J Psychiatry Med 1973; 4 (4): 379-87.

16. Summers R, Harker L. Ulcerative colitis and sensorioneural hearing loss: is there a relationship? J Clin Gastroenterol 1982; 4: 251-2.

17. Bachmeyer C, Leclerc-Laudgraf N, Laurette F, et al. Acute autoimmune sensorioneural hearing loss associated with Crohn disease. Am J Gastroenterol 1998; 93: 2565-7.

18. Scheid R, Teich N. Neurologic manifestations of ulcerative colitis. Eur J Neurol 2007; 14 (5): 483-93.

19. Davies P. Beethoven in Person: his deafness, illnesses, and Death. Greenwood Press, London 2001. 